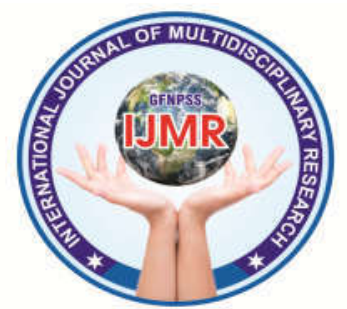

\title{
EFFECT OF ELECTRONIC GADGETS IN SCHOOL GOING CHILDREN
}

\section{MR. ARVIND KUMAR ${ }^{1}$ DR. YOGESH YADAV ${ }^{2}$}

${ }^{1}$ Ph.D. Scholar, M.V.G.U. Jaipur \& Asso. Professor, Devi Institute of Nursing Jaipur (Raj.)

${ }^{2}$ Dean \& Principal, Maharaj Vinayak Global University,Jaipur (Raj.)

Corresponding Email: arvindsanju83@gmail.com

BACKGROUND OF THE STUDY: Learning is made easy with a wide range of electronic stuff helping in studying. Presently, we see students are using tablets instead of notebooks. This is definitely a great changeover. Students are so attracted to the electronic gadgets that they forget what they are up to.

Keywords: Effect, Electronic gadgets, school going children

\section{INTRODUCTION:}

It is a pathetic situation. Though electronic gadgets have made learning concepts easier by providing interactive videos, graphical interpretation and more but, they have adversely affected kid's life. The young generation gets manipulated easily with upcoming trending gadgets. If electronic gadgets are used in a limit then it has fewer effects on humankind. There are advantages of gadgets as they have made our lives easier but they have disadvantages as well. We have listed out a few major effects of electronic gadgets used by students. In the current world we can see technology has been an integral part of our lives. It definitely plays an important role in our day to day life. Technology has drastically increased at a fast pace developing new gadgets frequently. From a young age to old age, we see everyone using electronic gadgets. It might be TVs, smart phones, laptops, tablets, and so on. The list goes long if we star listing out each gadget entered into the market. Technology has replaced a human life in various ways including studying.

Increases Aggression: Generally, we see children replicating what they see or hear. Electronic gadgets like TVs, mobiles, laptops show various kinds of entertainment shows and much other violent stuff. Even Children involve themselves in surfing unwanted things, chatting and much more. These can result in a huge impact on a Children's life. Children interaction with the social media and gadgets increases their aggression abruptly with the increased use of 


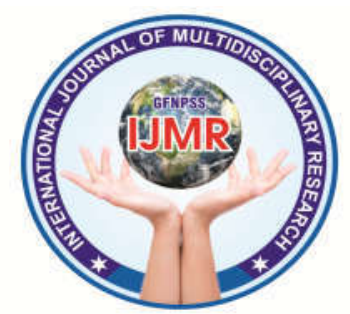

electronic stuff; innocent Children's can be a victim of themselves.

Causes Sleep Disorders: Students are so much addicted to mobiles and laptops that they spend whole night playing games, surfing, chatting, and so on. This can be dangerous. Parents have to educate children on how to use gadgets wisely. Children need adequate sleep to stay active whole day but the current generation children are more on phones and laptops. Moreover, the rays emitted by screens lead to loss of vision.

Leads to Obesity: Children don't show interest in playing outdoor games as they are stuck on to the mobiles and tablets. Along with this, Children tend to eat a lot of junk food without conscious of the amount of intake. This can lead to obesity. They don't realize at an early stage but they might have to face hurdles in life.

Causes Hearing Problems: Children and teenagers tend to use mobiles and tablets wearing earphones and headphones with more volume. This will cause damage to their ears and they may become deaf. Wearing earphones is not restricted but you need to maintain less volume and less time. Children use the phones the whole day their earphones which is dangerous.
Dries up the Eyes: All electronic devices emit light rays which are harmful. Continuously watching electronic devices for a long time may lead to visually impaired. The liquid present in the eyes may dry up and cause a vision problem. It is one of the major impacts of using gadgets.

Increased chances of Cancer: The radiation from electronic gadgets is a cancer - causing agent that may lead to cancer problems. Children may be affected widely with various types of cancers like leukemia, skin, thyroid, breast, and stomach cancers.

Activates Back Pain: One of the major health issues caused by using gadgets is back pain. Children are unaware of this but it does affect them slowly. Children tend to stick at one place using electronic gadgets continuously for a long time which results in back pain.

Hence, this is an initial warning for children using too many electronic gadgets. It is not mandatory that using gadgets has to stop immediately. Instead, use it in a limit. Fix yourself some time for using gadgets and then get back to other work. Do not use gadgets too much. 


\section{REFERENCES:}

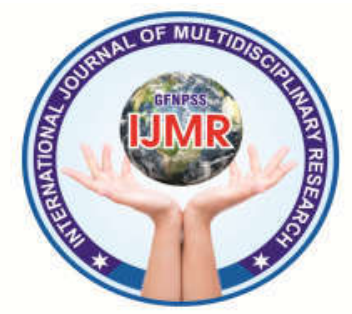

1. Joys M. Black, Text Book of Medical

5. American Academy of child \& surgical nursing, $8^{\text {th }}$ edition; volume 2 , adolescent psychiatric, Dec. 2014:13 Elsevier publication, 2008;

6. The influence of media \& technology

2. www.google.com on football, Weebly.com

3. Wikipedia.

7. The Detrimental Effects of TV On

4. Mary L Graving; "How TV affects Children, Brightkite.com your child". $6^{\text {th }}$ October 2008 